\title{
Using PhysX Simulation Fire Model of Backdraft in Unity 3D Game Engine
}

\author{
Yongzhe $\mathrm{Xu}^{1}$, Eunju $\mathrm{Kim}^{1}$, Kyunjoo $\mathrm{Lee}^{2}$, Jaesug $\mathrm{Ki}^{1, *}$ and Byungsoo Lee ${ }^{1, *}$ \\ ${ }^{1}$ Department of Computer Engineering, Incheon National University, Korea \\ ${ }^{2}$ MaxOn Soft, Co., Ltd, Korea
}

yongzhexu@hotmail.com,lisun@maxonsoft.com,leebone28@hanmail.net.)

\{skyblueki,bsl\}@incheon.ac.kr

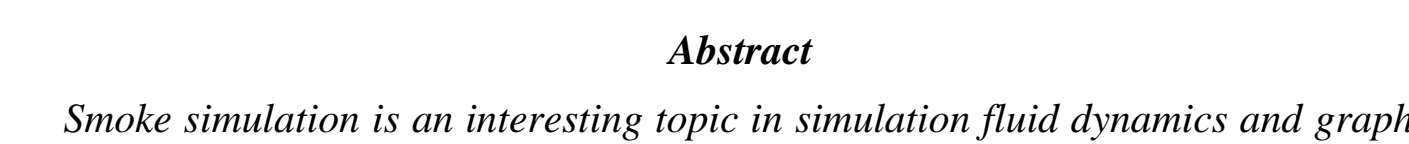
area.

Main research area is simulation Backdraf physicat unity 4.2.1f4 version. The Unity 3D game engine 4.2 versions have been start support PhysX. From Game Smoking part using Fluvio 2.1.0 Mutiphasic Simulation smoke effect, Smoke Coordinate based on FDS Simulation. When finefighters discover and search a building fire survivor pulling air into itself, they generally evacuate immediately, because this is a strong indication that a backdraft is imminent. Due to pressure differences, puffs of smoke are sometimes drawn back into the enclosed space from which they emanated, which is how the term backdraft originated. Backdrafts are very dangerous, often surprising even experienced firefighters. The most common tactic used by firefighters to defuse a potential backdraft is to ventilate a room from its highest point, Allowing the heat and smoke to escape without igniting explosively. The paper moin goal is focus on simulation naturally fire model of backdraft. Use the Simulation data in Unity 3D game Engine. After computing the coordinates and explosion of Unity 3D cimple particle system of Fluvio 2.1.0 and PhysX discuss moving location boundary and physically effects, make them flow like simulation's real world smokefluid and physically support fire effect backdraft model.

Keywords: Computer Graphics, Fire Dynamics Simulator (FDS), Smoke, Particle System, Fluid Dynamics, Unity 3D, Fire Simulation

\section{Introduction}

Simulation backdraft fire model is not graphic effect problem. NIST (National Institute of Standards and Technology) NIST-GCR-94-64 [1, 8] discuss Backdraft Phenomena in this paper simulation focus in Exploratory Simulations. Unity 3D game engine has special support for smoke and fluid water. Naturally smoke game developer usually using fluid dynamics showing it [7]. The fire model of backdraft is very hard research area. Fire, Air, Material, fire burning time, environment, all this thing change backdraft happen or not [11]. The most common use of the term flashover is to describe the near-simultaneous ignition of material caused by heat attaining the auto ignition temperature of the combustible material and gases in an enclosure; flashovers of this type are not backdrafts as they are caused by thermal 
change. Backdrafts, however, are caused by the introduction of oxygen into an enclosure that may already be hot enough for ignition; thus, backdrafts are caused by chemical change [10].

\section{Related Works}

Backdraft: The picture 1, 2 shows "Video catches backdraft that injured 4 Chicago firefighters". Chicago Breaking News Center. 2010-03-10. Retrieved 2011-06-11. The video included with this news item of a major backdraft incident is now being used for firefighter training [9].

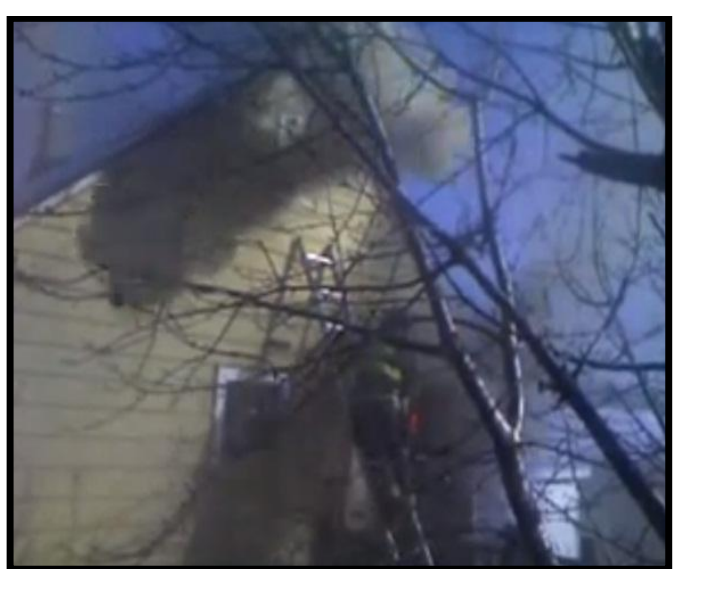

Figure 1. Backdraft in House

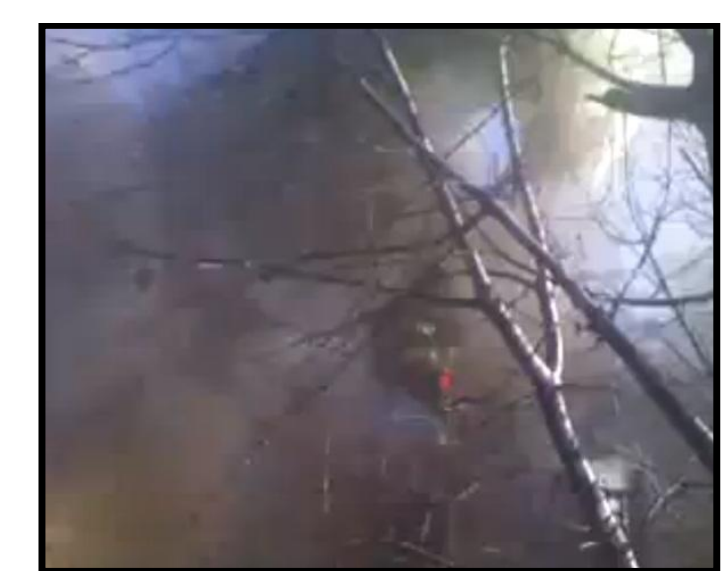

Figure 2. Backdraft Happened

\subsection{Backdraft and Flashover}

What is a backdraft explosion and how does differ from a flashover? Explosions kill and injure firefighters inseveral ways The blast can blow a firefighter across a street; flying glass and shrapnel an decapitate a firefighter; flame accompanying the explosion can cause serious burns and an explosion can collapse walls, partitions and iron shutters, crushing firefighters beneath them A backdraft is one type of explosion that occurs at fires. A backdraft is a smoke explosion. Smoke is the fuel in the fire triangle of a backdraft. The explosive smoke is carbon monoxide (CO). $\mathrm{CO}$ has an explosive range of 12 to 74 percent when mixed with air. Fire protection engineers classify explosions into two broad categories: physical explosions such as a BLEVE (Boiling Liquid Expanding Vapor Explosion) and chemical exprosions such as a combustion explosion. A backdraft would be classified as a chemical explosion. The same chemical reaction and explosive ingredients are present in a backdyaft, as are in any ordinary combustion explosion: fuel, oxygen and heat [12]. The fuel in a combustion engine explosion driving and automobile is gasoline; the fuel in a backdraft explosion is smoke. Fire protection engineers define the term explosion as an "effect" produced by a sudden violent expansion of gases. Some "effects" of an explosion are shock waves, which can shatter windows, blow down firefighters and collapse walls [3].

\subsection{Fire Color of Temperature?}

From Human visual system saw fire temperature color in frequency of energy. Temperatures of flames by appearance he temperature of flames with carbon particles emitting light can be assessed by their color: Red Just visible: $525^{\circ} \mathrm{C}\left(980{ }^{\circ} \mathrm{F}\right)$, Dull: $700{ }^{\circ} \mathrm{C}$ $\left(1,300{ }^{\circ} \mathrm{F}\right)$, Cherry, dull: $800{ }^{\circ} \mathrm{C}\left(1,500{ }^{\circ} \mathrm{F}\right)$, Cherry, full: $900{ }^{\circ} \mathrm{C}\left(1,700{ }^{\circ} \mathrm{F}\right)$, Cherry, clear: 
$1,000{ }^{\circ} \mathrm{C}\left(1,800{ }^{\circ} \mathrm{F}\right)$ Orange: Deep: $1,100{ }^{\circ} \mathrm{C}\left(2,000{ }^{\circ} \mathrm{F}\right)$, Clear: $1,200{ }^{\circ} \mathrm{C}\left(2,200{ }^{\circ} \mathrm{F}\right)$, White : Whitish: $1,300{ }^{\circ} \mathrm{C}\left(2,400{ }^{\circ} \mathrm{F}\right)$, Bright: $1,400{ }^{\circ} \mathrm{C}\left(2,600{ }^{\circ} \mathrm{F}\right)$, Dazzling: $1,500{ }^{\circ} \mathrm{C}\left(2,700{ }^{\circ} \mathrm{F}\right)$ [4].

\subsection{Backdraft Scenario}

Propose Backdraft Fire Model, Unity 3D game engine, FDS From simulation part design Backdraft experiment environment like Figure 3 shows simulation side view of mesh. Figure 2 shows side view environment. The FDS experiment sample change FDS sample code only simulation bigger Container to find about backdraft effect fire model. Environment mesh $\mathrm{X}$, $\mathrm{Y}, \mathrm{Z}=36,36,36 \mathrm{M}$ and Container size $\mathrm{X}, \mathrm{Y}, \mathrm{Z}=3,12,3 \mathrm{M}$. This model simulation time need invisible. Figure 3, 4 shows about invisible scene. Inside container box smoke detector ${ }^{\circ}[2]$ each position is $\mathrm{X}, \mathrm{Y}, \mathrm{Z}=0.25 \mathrm{X} 0.25 \mathrm{X} 0.25$ smoke detector sensor outside of box each position is $\mathrm{X}, \mathrm{Y}, \mathrm{Z}=0.3 \mathrm{X} 0.3 \mathrm{X} 0.3$ distance little bigger than inside $[5,14,15]$.

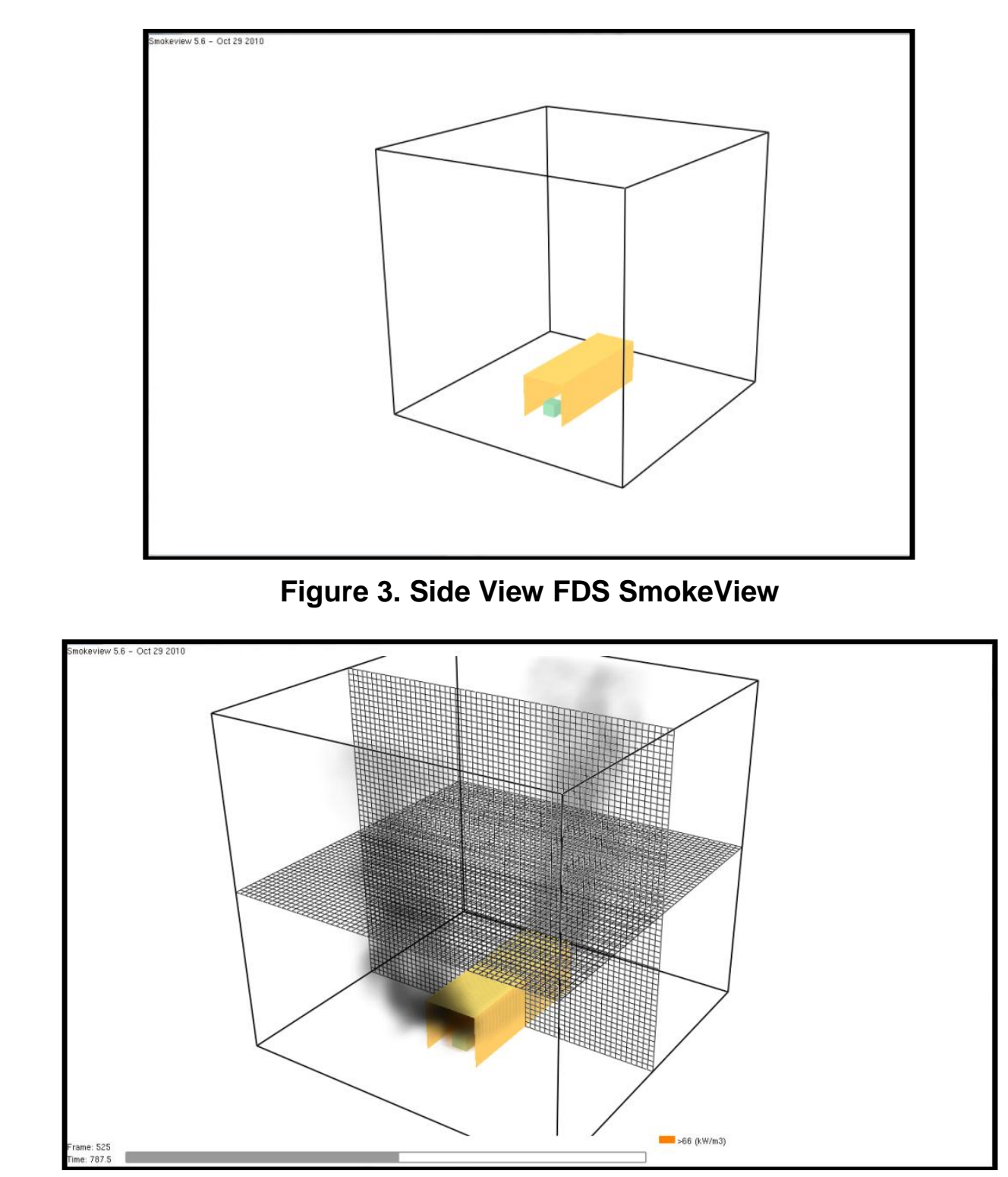

Figure 4. Fire Burning Computer Fire Temperature and Smoke Fluid 


\subsection{Fluvio 2.1.0}

Fluvio 2.1.0 is Unity 3D package (version 4) simulation particle fluid model in game scene. This model can effect water and fire model [6] Fluid dynamics on all platforms. Fluvio currently supports all platforms (except for Flash currently). Console developers: Fluvio is Thinksquirrel's middleware solution for real-time fluid dynamics. With both a 2D and 3D solver, Fluvio can simulate accurate fluid physics including but not limited to:

Incompressible/slightly compressible fluid dynamics

Liquids and gasses (fire, volumetric smoke)

Fluid interaction (oil and water)

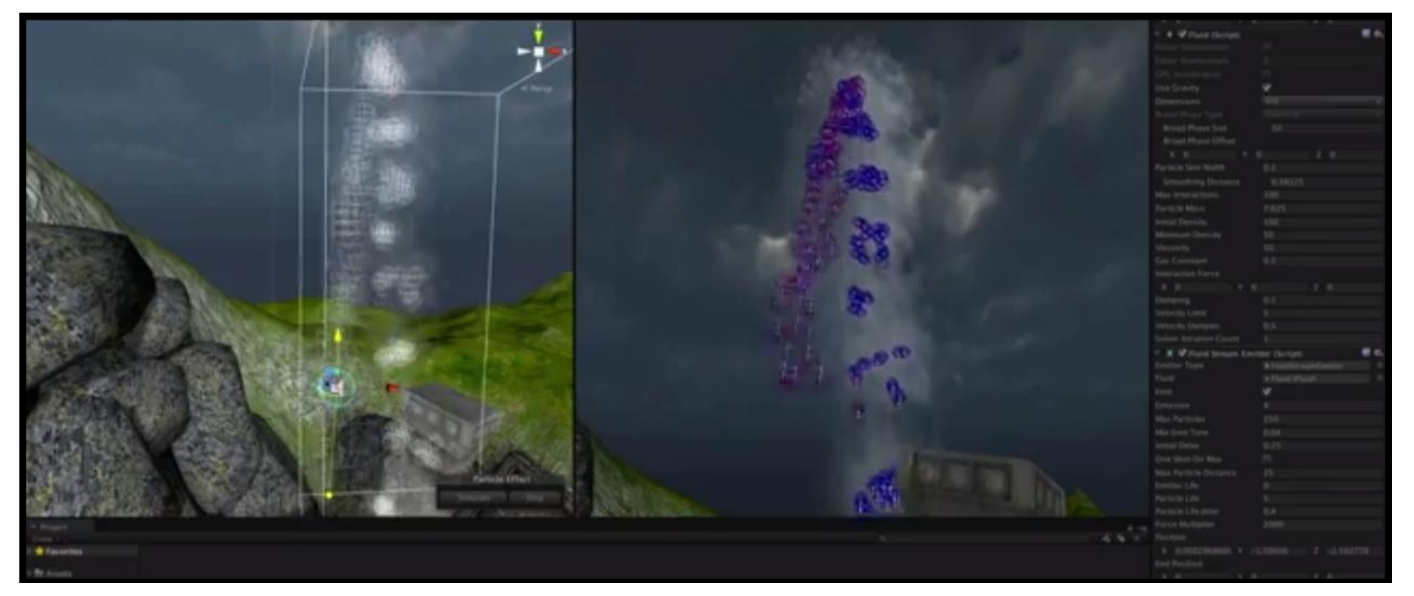

Figure 5. Fluvio 2.1.0 Particle Fluid Simulation in Unity 3D Game Engine

\subsection{Function of Particle Radius and Backdraft Scale}

Particle radius and Backdraft Scale use function to design radius grow up X, Y, Z space and backdraft scale explosion power using function to compute it's power. All function based on NIST method [1].

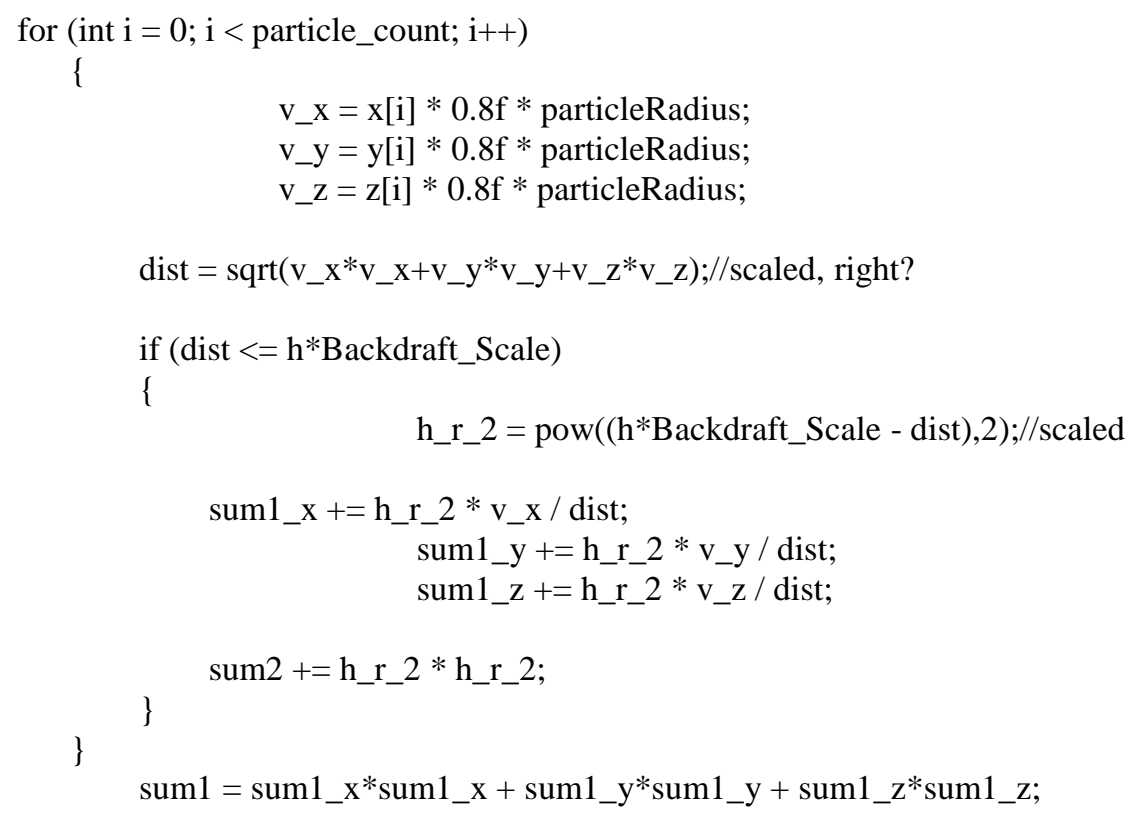




\section{Unity 3D Backdraft Event TimeLine}

Design fire model of Backdraft $1^{\text {st }}$ using event manager class in cross compile code. It listening about game event call find about event. In Backdraft if firefighter not open up building window or gas event catch all these event to judgment about Backdraft will happened, but in nature physically fire model Back draft happen not easy to computing but Backdraft only happened in close space fire time line near ending time. $2^{\text {nd }}$ Class Event Manager computing listening event and event manager time line. Backdraft time happened after Strong power fire 4 6 minute. The event time line figure and discuss. Class Event Manager is listener detection Backdraft time and user game avatar region. When event handler is happen, transform all status (game avatar status, region, BackdraftPower) to Backdraft fire model Scenario. Class Event Manager flow Figure 6 event time.

\section{Class Event Manager \\ template <class ProducerClass, class ListenerClass, class EventClass>> void EventManager::listen( \\ shared_ptr<Backdraft> timeline, \\ string event_name, \\ shared_ptr<EventManager> listener, \\ void (ListenerClass::*method)(EventClass * event) \\ boost::function $1<$ void, EventClass $*>$ bound method = boost::bilyd(method, listener, _1);}

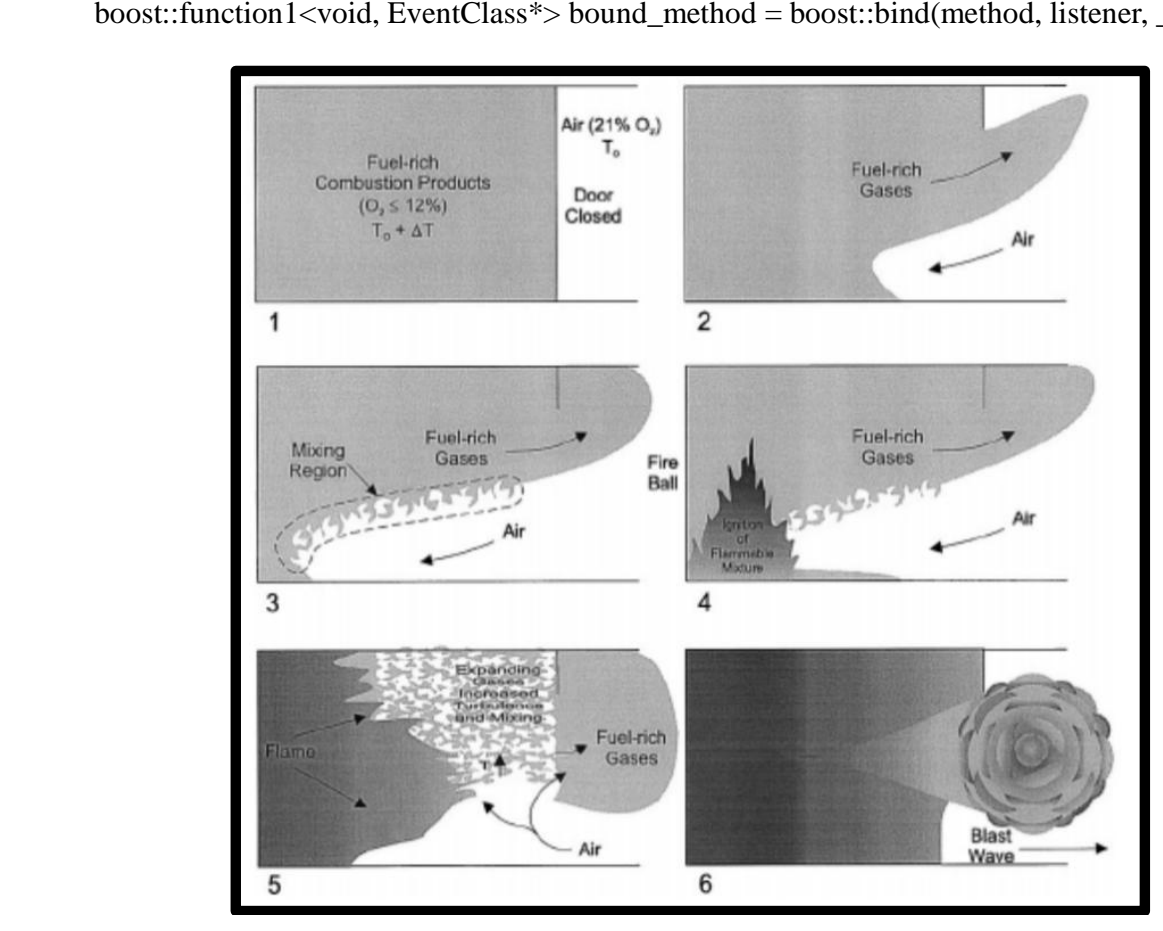

Figure 6. Progression of a typical Backdraft (Source:Gottuk,D.)

\section{Experiment}

Figure 7 shows experiment all line count about smoke, fire, oxygen to compute backdraft power. Side line middle line shows these. Smoke density using smoke device to record value. Figure 8 is Smoke device in $0.5 \mathrm{~m}$ X $0.5 \mathrm{~m}$ X $0.5 \mathrm{~m}$ it means $1 \mathrm{~m} \mathrm{X} 1 \mathrm{~m} \mathrm{X} 1 \mathrm{~m}$ cube have 27 record value points. Red circle is smoke device position point. 


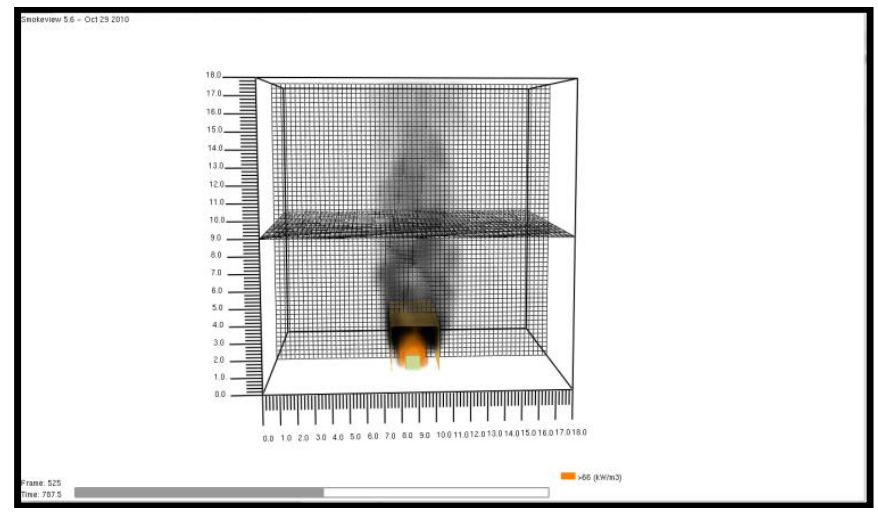

Figure 7. The Fire Model Backdraft

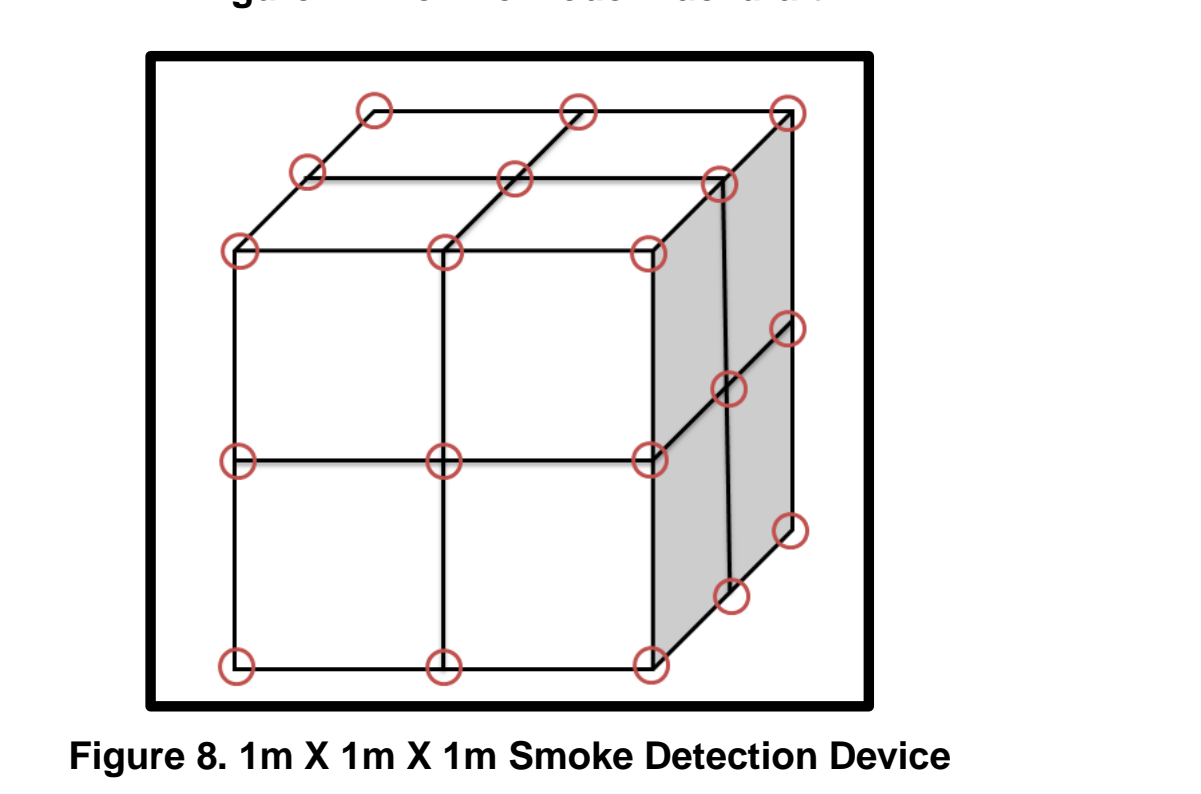

\subsection{Backdraft Scenario Time Line}

Unity 3D game engine based animation event. The Unity 3D game engine of fire model backdraft used ppecified points of game scenario timeline. Some game scene event handler to detection user false action. Animation import and animation scripting input in backdraft timeline. Backdraft Script is linkage Unity 3D Animation Event, Animation State info, Animation State. Add FDS Excel result explosion to Script. The trigger effect of "Time Line Event. "Class Event Manager", "Game user Avatar" and "Backdraft explosion scale" are happen. Animation and PhysX system compute damage and effect in game.

\subsection{Proposal System Flowchart}

Figure 9 shows proposal system flowchart. 1st copy game environment value to FDS (Building structure diagram, Burner position, Burning Material, wind). 2nd Add Smoke detection device in simulation environment. 3rd Combine Excel file, Backdraft Event Timeline and Backdraft Scenario Timeline to Unity 3D game Engine. 


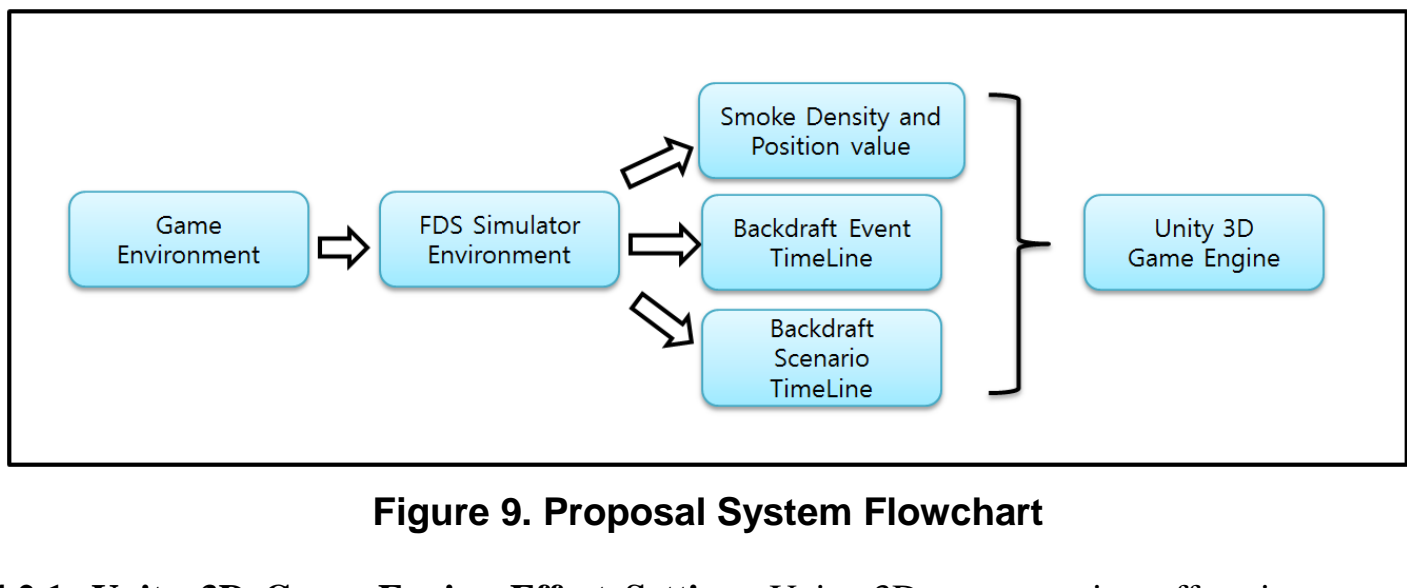

4.2.1. Unity 3D Game Engine Effect Setting: Unity 3D game engîne effect input need physX. Simulation fire object and add Backdraft Event Timeline connect to 3D physics the main concept is different component. 3D physics Rigidbody component and Script Animation state.

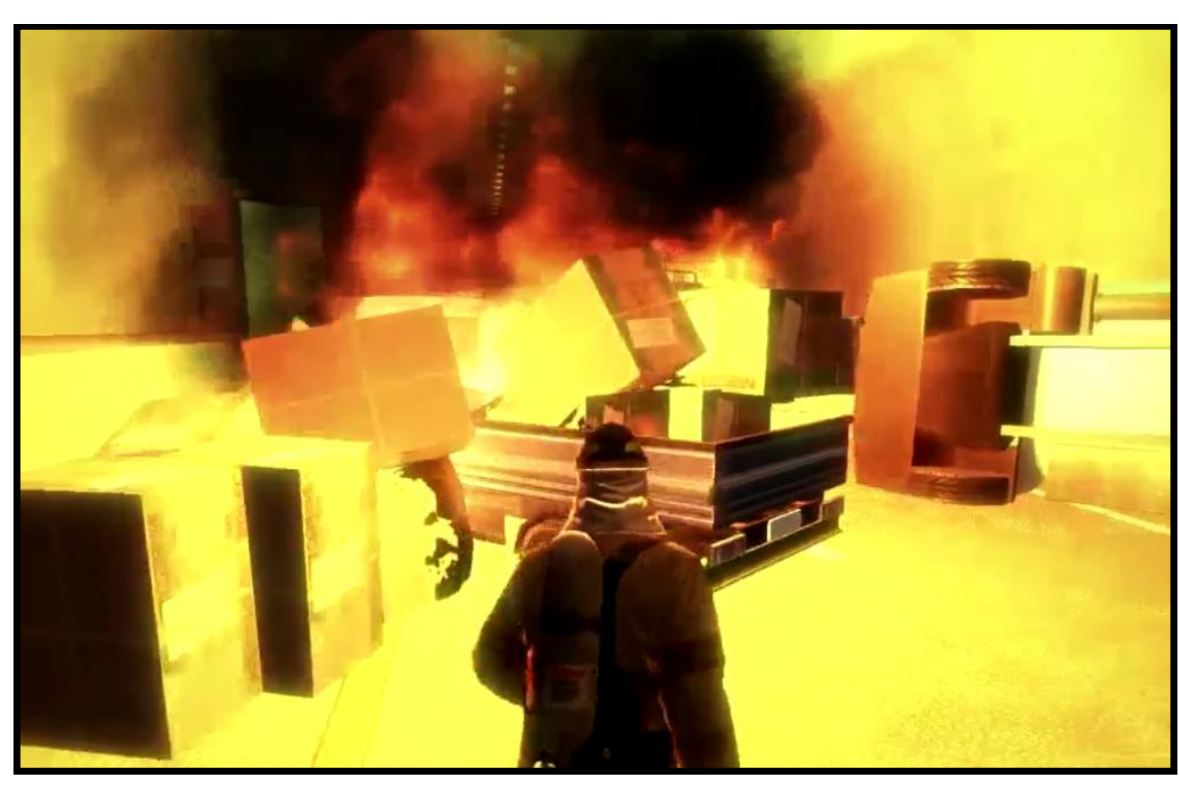

Figure 10. Unity 3D Game Engine Fire with PhysX

\section{Conelusion and Future Work}

Simulation fire model is very hard research so in this paper make one time line and energy power method simulation that part. Simulation nature backdraft very hard and computing time is long time so using event manager to do it all these methods help Unity 3D Game Engine to shows Backdraft shocking explosions. This method can training firefighter to know about which time which place maybe it is happened. Training result make game engine look like more realism. Fluvio also help fire energy fluid shows damage particle method compute radius and power. These all method design simple because if complex method Unity 3D game engine can't run in real-time. Future, multi-player system combines in all proposal game. Research focus on multi-player and Debriefing system. 


\section{Acknowledgements}

This paper was Researched (2012 2014) The Next Generation Fire protection \& Safety Core Technology Development program of National Emergency Management Agency (NEMA) of Republic Korea.

\section{References}

[1] M. Macklin and M. Muller, "Position Based Fluids", ACM TOG 32 2003, (2003).

[2] X. Yongzhe, K. Lee, E. Kim, J. Ki and B. Lee, "Simulation of Smoke to Improve Unity 3D Game Engine Particle System based on FDS", SofTech, (2013).

[3] V. Dunn, "Deputy Chief F.D.N.Y.firefighting strategy and tactios training", http://vincentdunn.com/dunn/newsletters/dec/dec.pdf.

[4] Steve DeRose's Engineering Tables Page-Flame http://www.derose.net/steve/resources/engtables/flametemp.html.A

[5] G. P. Forney, "User's Guide for Smokeview Version 5 - A Tool for Visualizing Fire Dynamics Simulation Data”, NIST Special Publication 1017-1 CODEN:NSPJE2 Fire Research Diysion Building and Fire Research Laboratory, (2007) August.

[6] Unity Team, Unity Manual, Particle System, positioning Game Objects

[7] B. Throop, "Detonator parametric Explosions for Unity," 2009) September.

[8] A. Horvat and Y. Sinai, "Numerical Simulation of Backdraft Phenømena. Manuscript published in Fire Safety J.”, Elsevier, vol. 42, Issue 3, (2007), pp. 209-209.

[9] Yoonhoseo, "A Planning Study on Testbed Implementation of Training Simulator for Fire Fighting based on Tangible Technology", NEMA-2010(Project Report, (2010).

[10] H. Ma, "Illustrative description to the GB50045-95. Code for Fire Protection Design Tall Buildings, Public Co. China", (1995) - In Chinese.

[11] G. E. Gorbett, "CFPS, MIFireE, The Current/Rnowledge and Training Regarding Backdraft, Flashover, and Other apid Fire Progression Phenomena", (2004) June.

[12] R. Zalosh, "Blast waves and fireballs generated by hydrogen fuel tank rupture during fire exposure", Wellesley .

[13] D. Staubach, "Smothed Particle Hydrodynamics Real-Time Fluid Simulation Approach",

[14] M. Kevin, K. Bryan, H. Simo and F. Jason, "Fire Dynamics Simulator (version 5)", NIST Special Publication 1019-5, NIST

[15] G. P. Forney, “User's Gaide for Smokeview Version 5 - A Tool for Visualizing Fire Dynamics Simulation Data, NIST Speciaß Publication 1017-1 CODEN:NSPUE2, Fire Research Division Building and Fire Research Laboratory, (2007) August.

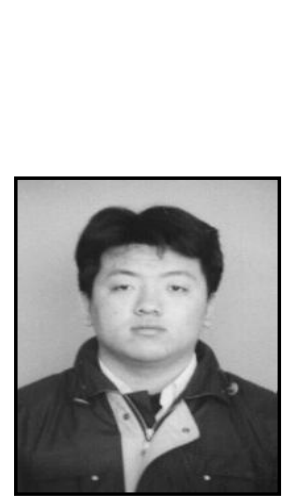

\section{Authors}

Yongzhe $\mathbf{X u}$, he received his MS in Computer science and engineering from University of Incheon, Korea, in 2009. He is currently working toward a $\mathrm{PhD}$ in computer science and engineering at the same university. His research interests include computer graphic, FDS, virtualization, and Pattern Recognization, Machine Learning. 


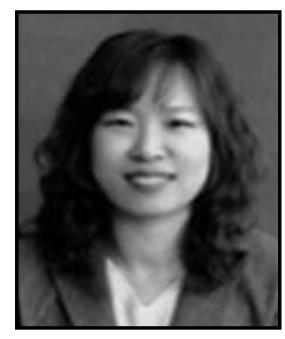

EunJu Kim, she received her MS in computer science and engineering from University of Incheon, Korea, in 2010.

She is currently working toward a $\mathrm{PhD}$ in computer science and engineering at the same university. Her research interests include computer vision, image processing, and Artificial intelligence.

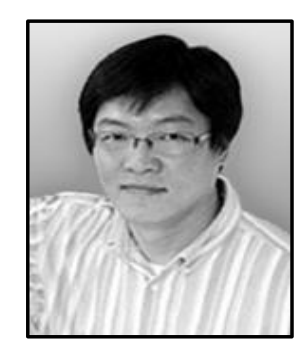

Kyunjoo Lee, he received his bachelor's degree in Departmeht of Philosophy from korea university in 1991, 1993-1999 种像音 CEO, 1999-2001 Oz Intern Media project chief, 2001-2002 Muhon virtual Society Game team leader, 2002-2013 MaxonSoft CTO. His interesting about multi-platform game, fire protection training game, 3D Game engine

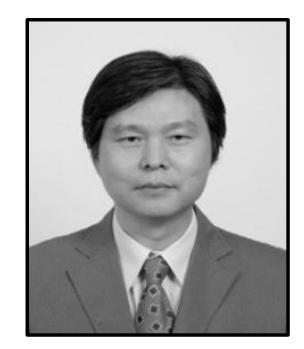

Jaesug Ki, he received his doctor of Department of industrial engineering from than Yang Uniersity in 1993. 1993-2000 associate professor in Kangwon National Unversity. 2000-2006 a laboratory chief in KCI. His interesting about fire protection training simulation, sports training simulation, National Defense weapon simulation

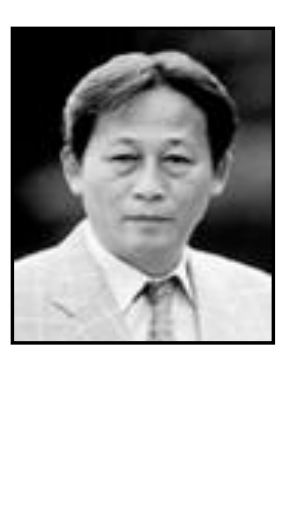

Byungsoo Lee, he received his MS in MBA from University of Dongguk, Korea ,1980. Received his Doctor of Science from University of KyongGi, Korea, $1998 \mathrm{He}$ is an Professor of Department of Computer Engmeering at the University of Incheon, Korea. His research interests nclude software design, decision making system, eCRM, RFID/USN, IT convergence 
International Journal of Multimedia and Ubiquitous Engineering Vol.9, No.6 (2014)

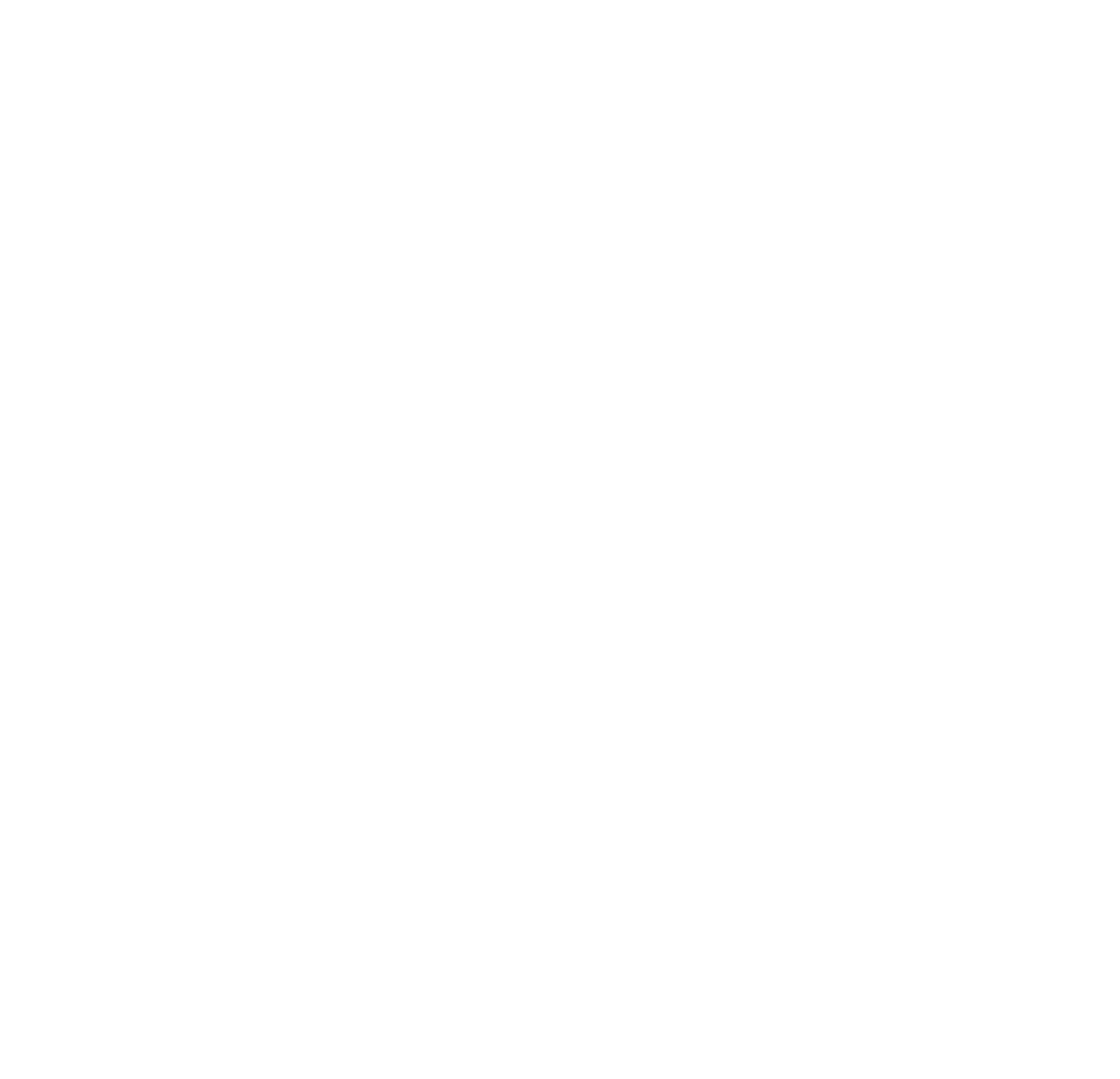

